\title{
Bullwhip Entropy Analysis and Chaos Control in the Supply Chain with Sales Game and Consumer Returns
}

\author{
Wandong Lou ${ }^{1}$, Junhai Ma ${ }^{1, *}$ and Xueli Zhan ${ }^{1,2, *}$ \\ 1 College of Management and Economics, Tianjin University, Tianjin 300072, China; wd1160211@126.com \\ 2 School of Economics, Beijing Wuzi University, Beijing 101149, China \\ * Correspondence: mjhtju@aliyun.com (J.M.); xuelz20163205@126.com (X.Z.); Tel.: +86-22-2789-2371 (J.M.) \\ Academic Editor: J. A. Tenreiro Machado \\ Received: 29 November 2016; Accepted: 3 February 2017; Published: 10 February 2017
}

\begin{abstract}
In this paper, we study a supply chain system which consists of one manufacturer and two retailers including a traditional retailer and an online retailer. In order to gain a larger market share, the retailers often take the sales as a decision-making variable in the competition game. We devote ourselves to analyze the bullwhip effect in the supply chain with sales game and consumer returns via the theory of entropy and complexity and take the delayed feedback control method to control the system's chaotic state. The impact of a statutory 7-day no reason for return policy for online retailers is also investigated. The bounded rational expectation is adopt to forecast the future demand in the sales game system with weak noise. Our results show that high return rates will hurt the profits of both the retailers and the adjustment speed of the bounded rational sales expectation has an important impact on the bullwhip effect. There is a stable area for retailers where the bullwhip effect doesn't appear. The supply chain system suffers a great bullwhip effect in the quasi-periodic state and the quasi-chaotic state. The purpose of chaos control on the sales game can be achieved and the bullwhip effect would be effectively mitigated by using the delayed feedback control method.
\end{abstract}

Keywords: supply chain; bullwhip effect; sales game; nonlinear characteristics; chaos; consumer returns; entropy

\section{Introduction}

With the wide diffusion of e-commerce and the increasingly fierce competition all over the world, online retail channels have been developing rapidly. In China, as of December 2015, the number of netizens reached 688 million [1], including 413 million online shopping users, whose ratio had increased to $60 \%$ [2]. A number of online retail oligarchs have emerged with the rapid development of the internet sales platform and network direct sales. There are both distributors and retailers buying products directly from the manufacturer, and selling to consumers through the network platform. For example, many products are sold through WalMart and Jingdong Mall at the same time, where the former is a traditional super retail firm and the last is new online super retail platform. The prices at WalMart may be properly higher than the prices on Jingdong Mall, but most of the time they offer relatively stable prices, and both retailers take sales as the goal of the competition through service and reputation. Considering the supply chain system is a complex network system, these sales games between retailers often bring demand variability which leads to a common phenomenon called the bullwhip effect [3].

Many scholars have devoted time to the study of the bullwhip effect, including demand processes and forecasting techniques. In the research on the bullwhip effect in the supply chain, the actual demand model is very important. Lee et al. [3] assumed that the actual demand is subject to a 
first-order autoregressive AR(1) time series, and established the direction for the quantitative of the bullwhip effect. Luong and Phien [4] were the first to deal with the second-order autoregressive AR(2) and the $p$ th-order autoregressive $\operatorname{AR}(p)$ demand process and give the corresponding expression of the bullwhip effect. Gilbert [5] presented a multistage supply chain model based on Autoregressive Integrated Moving Average (ARIMA) time-series models. Duc et al. [6] investigated the effects of the autoregressive coefficient, the moving average parameter, and the lead time on the bullwhip effect, under the Autoregressive Moving Average model (ARMA(1,1)). Gaalman and Disney [7] investigated the behavior of the proportional order up to policy for $\operatorname{ARMA}(2,2)$ demand with arbitrary lead-times. Buchmeister et al. [8] experimented (by simulating) with a special case of a simple three-stage supply chain using seasonal and deseasonalized time series of the market demand data in order to identify, illustrate and discuss the impacts of different level constraints on bullwhip effect. Nepal et al. [9] presented an analysis of the bullwhip effect and net-stock amplification in a three-stage supply chain considering step-changes in the production rates during a product's life-cycle demand. The simulation results showed that performance of a system as a whole deteriorates when there was a step-change in the life-cycle demand. Nagaraja et al. [10] measured the bullwhip measure for a two-stage supply chain with an order-up-to inventory policy and derived for a general, stationary SARMA demand process. Wang and Disney [11] investigated the amplification of order and inventory fluctuations in a supply chain model with stochastic lead-time, general auto-correlated demand and a proportional order-up-to replenishment policy. They gave conditions for the ability of proportional control mechanism to simultaneously reduce inventory and order variances. For $\operatorname{AR}(2)$ and $\operatorname{ARMA}(1,1)$ demand, both variances can be lowered under the proportional order-up-to policy.

Because demand forecasting is one of the key causes of the bullwhip effect, many have scholars sought to develop many forecasting methods and inventory control systems to fulfill the demand within the lead time. Chen et al. [12,13] quantified the bullwhip effect in a simple, two-stage supply chain consisting of a single retailer and a single manufacturer by using a moving average (MA) method and an exponential smoothing (ES) method. Luong [14] proposed the minimum expected mean squares of error forecast method (MMSE) for lead-time demand to measure the bullwhip effect in supply chains with AR(1) processes. Wang et al. [15] gave a comparison of the bullwhip effect in a single-stage supply chain for series demand function modela $\operatorname{ARiMA}(1,0,0), \operatorname{ARiMA}(0,0,1), \operatorname{ARiMA}(1,0,1))$ by using the Correct, MA, and EWMA (Exponentially Weighted Moving Average) methods. Ma et al. [16] found and compared the analytic expressions of the bullwhip effect on product orders and inventory using minimum mean-squared error, moving average and exponential smoothing forecasting techniques. Bray and Mendelson [17] analyzed the bullwhip by information transmission lead time based on public companies' data from years 1974-2008. Shorter reaction times cause significantly more trouble regarding bullwhip. Csik and Foldesi [18] tested the problem of bullwhip effect by adoption of an inventory replenishment policy involving a variable target level. Safety stock was proportional to the actual demand. They proposed a new production plan, which guarantees the stability of the entire supply chain. Costantino et al. $[19,20]$ proposed a SPC (Statistical Process Control) forecasting system based on a statistical control chart approach to handle the trade-off between order variability amplification and inventory stability and compared with MA and ES methods in a four-echelon supply chain. Simulation comparisons showed that their system outperformed both the smoothing order-up-to policy and the Min-Max inventory policy in terms of bullwhip effect and inventory performances.

A few scholars have applied the theory of entropy to the supply chain management. An entropy-based formulation was proposed by Martínez-Olvera [21], as the basis of a methodology for comparing different information sharing approaches in a supply chain environment. He also presented a step-by-step comparison of two different information sharing approaches. Durowoju et al. [22] proposed an approach to assess the impact of information disruption using entropy theory coupled with simulation methodology.

Most of the above researches considered only one retailer. Therefore, their demand models can't include the impact of competition between retailers (Duc et al. [23]). Retailers in the supply chain 
system, in order to gain a greater market share, often adopt a strategy of increasing sales, i.e., they take the sales as the decision-making variable of the competition game. For the interaction behavior between customers and suppliers, the supply chain must exhibit deterministic chaos, and there will be attractors of the model moving with the environment and the initial states ( $\mathrm{Wu}$ and $\mathrm{Zhang}$ [24]). The investigation of the supply chain dynamics from chaos perspective and quasi-chaos perspective is meaningful (Hwarng et al. [25,26]). Especially, when two supply chains take the Cournot competition affected by supply uncertainty, retailers should adopt corresponding order and inventory strategies (Fang and Shou [27]).

To the authors' knowledge, there is lack of an investigation about how the bullwhip effect and entropy are affected by retailers' sales game based on the bounded rationality from a complex perspective. In particular, for online retailers there is a statutory policy called 7 days no reason return, which is not applicable to traditional retailers. The sales game of retail oligarchs and online retailers' returned products will result in fluctuations of demand, orders, and inventory, therefore, it is necessary to study their profits and bullwhip effect under sales competition. In particular, when the retailers forecast the expected sales volume and the returns volume for the next period, they often consider whether they can achieve more profits, and don't just consider the past demand information. Therefore, the objective of this paper is to investigate the case of sales competition and return rate with bounded rationality between retailers.

This paper contributes to the existing literature regarding bullwhip effect in several ways. Firstly, this paper gives a framework for investigating the bullwhip effect on the basis of the sales game with weak noise between traditional retailers and online retailers. Secondly, this paper attempts to study the impacts of the sales adjustment speed on the bullwhip effect using the theory of complexity and entropy. Thirdly, this paper gives a new forecasting method (bounded rational expectation) for the bullwhip effect research. At the end, the impact of 7 days no reason for return policy statutory for online retailers is investigated regarding the profits of the both retailers.

This paper is organized as follows: in Section 2 we describe the problem and construct the model of the supply chain system. Section 3 analyses the complexity of the system, then, in Section 4, we design experiments and compare the bullwhip effect under three states through numerical simulations. Section 5 proposes a time-delay feedback method to control the system and mitigate the bullwhip effect. Finally, Section 6 presents the conclusions and insights of this study. Appendixs A-C which present the proofs of propositions are given after the conclusions.

\section{Problem Description and Model Construction}

In this paper, we establish a supply chain system that consists of one manufacturer and two retailers, one of which is a traditional retailer and the other is an online retailer. The two retailers sell similar products to a common market, and there is a competitive relationship between them as shown in Figure 1.

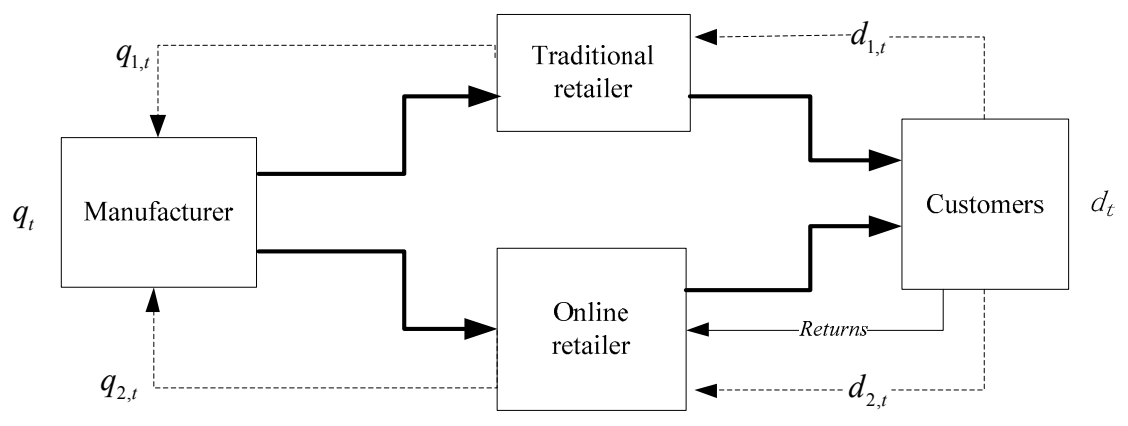

Figure 1. Supply chain model. 
Customers who purchase a product through online retailers can return it within 7 days without any reason because the 7 days no reason for return policy is statutory for online retailers and not applicable to traditional retailers. The returned products are assumed to satisfy the conditions to be sold again without any other costs. The products meeting the conditions will be returned to the online retailer, after a return cycle through its reverse logistics. In order to pursue greater profit and market share, retailers tend to adopt some strategy to increase sales. For example, they usually use advertising, promotions, and providing gifts and other ways to stimulate the desire of consumers to buy more, so as to achieve the purpose of improving the market demand for their products. We are working on the assumption that they both take the bounded rational decision to determine their sales volume. The retailers are both familiar with the market and can obtain the demand information of the current period for their products in a timely way. They use a sales game to forecast the sales volume (demand forecast) for the next period according to the bounded rationality expectation. The order-up-to inventory policy is assumed to be employed by the two retailers. Based on the current and the forecasted demand for the future, retailers estimate the order-up-to point and place their own orders. According to the orders submitted by retailers, the manufacturer delivers the products to the retailers and after a lead time, both retailers receive the products. Forecasting method, demand process, inventor-policy and some symbol notations are introduced in the following subsections.

\subsection{Notation}

Table 1 presents the operations management-related variables and parameters of the proposed supply chain model.

Table 1. Notations.

\begin{tabular}{cl}
\hline$a$ & the price ceiling of the product for the online retailer \\
$\bar{a}$ & the price gap between two retailers \\
$\theta$ & the impact factor of return rate on the price \\
$\varphi$ & the return rate \\
$\bar{\varphi}$ & the benchmark of the return rate \\
$b_{m n}$ & the impact of the sales volume on the price \\
$p_{i}$ & the price of retailer $i\left(i=T_{r}, O_{r}\right)$ \\
$d_{i, t}$ & demand (or sales) of retailer $i\left(i=T_{r}, O_{r}\right)$ at period $t$ \\
$c_{i}$ & the unit wholesale price for retailer $i\left(i=T_{r}, O_{r}\right)$ \\
$\varepsilon_{i, t}$ & Gaussian white noise for retailer $i$ \\
$\tau$ & the intensity of the noise \\
$q_{i, t}$ & the order quantity of retailer $i$ at period $t$ \\
$S_{i, t}$ & the order-up-to point of retailer $i$ at period $t$ \\
$\hat{D}_{i, t}^{L}$ & the estimated demand of retailer $i$ in the lead-time at period $t$ \\
$\hat{d}_{i, t}$ & the prediction of retailer $i$ 's demand at period $t$ \\
$\pi_{i, t}$ & the profit of retailer $i$ at period $t$ \\
$\alpha$ & the adjustment parameter of the traditional retailer in the game system \\
$\beta$ & the adjustment parameter of the online retailer in the game system \\
$L_{i}$ & the lead-time of retailer $i$ \\
$\hat{\sigma}_{t}^{L_{i}}$ & an estimate of the standard deviation of the forecasting error of the lead-time \\
$z$ & retailers' service level \\
$\sigma_{q}^{2}$ & the variance of the order \\
$\sigma_{d}^{2}$ & the variance of the demand \\
$\mu_{d}$ & the mean of the demand \\
$\mu_{q}$ & the mean of the order \\
$\mathrm{T}$ & the time length of the numerical experiment \\
\hline &
\end{tabular}

\subsection{Demand Forecasting with Bounded Rationality}

Suppose that retailers determine the demand forecasting in the next period with bounded rationality ( $\mathrm{Li}$ and $\mathrm{Ma}$ [28]), on the basis of the partial estimation of the marginal profit of their 
current period, i.e., the retailer will reduce its sales volume forecast for the next period if the current marginal profit is negative, the retailer will maintain its sales volume, if the current marginal profit is zero. Otherwise, the retailer will increase the sales volume in the next period.

In the same market, sales volume of both retailers have negative effect on their prices because of the similarity of their products, so the inverse demand function can be written as:

$$
\begin{gathered}
p_{T_{r}}=a+\bar{a}-b_{11} d_{T_{r}}-b_{12} d_{O_{r}} \\
p_{O_{r}}=a-b_{21} d_{T_{r}}-b_{22} d_{O_{r}}+\theta(\bar{\varphi}-\varphi)
\end{gathered}
$$

here, the parameter $a$ represents the acceptable price ceiling of the product for the online retailer. $\bar{a}$ is the price gap between the traditional retailer and the online retailer and the physical traditional retail price is usually higher than that of online retailer, i.e., $\bar{a}>0$. The parameters $b_{m n}$ determine the relationship between prices and sales, $b_{m m}(m=1,2)$ determine the impact of sales on their own prices, and $b_{m n}(m \neq n)$ determines the impact of their rival's sales on their own prices. The quotient $b_{m n} / b_{m m} \in(0,1)$, denotes the index of supply chain differentiation or supply chain substitution. The degree of supply chain differentiation will increase as $b_{m n} / b_{m m}$. The traditional retailer and online retailer are homogeneous when $b_{m n} / b_{m m}=1 . \varphi$ is the return rate and $\bar{\varphi}$ is the benchmark of the return rate which is considered normal by most consumers. $\theta$ is the impact factor of return rate on the price.

We assume that both retailers purchase goods from the manufacturer in accordance with the price of $c_{i}$, so we can respectively obtain the profit functions of the retailers:

$$
\begin{gathered}
\pi_{T_{r}}=d_{T_{r}}\left(a+\bar{a}-b_{11} d_{T_{r}}-b_{12} d_{O_{r} t}-c_{T_{r}}\right) \\
\pi_{O_{r}}=(1-\varphi) d_{O_{r}}\left(a-b_{21} d_{T_{r}}-b_{22} d_{O_{r}}+\theta(\bar{\varphi}-\varphi)-c_{O_{r}}\right)
\end{gathered}
$$

The marginal profits of two retailers can be calculated using the following expressions:

$$
\begin{gathered}
\frac{\partial \pi_{T_{r}}}{\partial d_{T_{r}}}=a+\bar{a}-c_{T_{r}}-2 b_{11} d_{T_{r}}-b_{12} d_{O_{r}} \\
\frac{\partial \pi_{O_{r}}}{\partial d_{O_{r}}}=\left(a-c_{O_{r}}-b_{21} d_{T_{r}}+\theta(\bar{\varphi}-\varphi)-2 b_{22} d_{O_{r}}\right)(1-\varphi)
\end{gathered}
$$

When the retailers adopt a sales game, they consider some existing sales information and their own marginal profit. If the marginal profit is greater than zero, the retailer can increase sales on the basis of the current sales volume. Retailers can give the forecast demand for the next period according to the bounded rational expectation:

$$
\left\{\begin{array}{l}
\hat{d}_{T_{r}, t}=d_{T_{r}, t-1}+\alpha d_{T_{r}, t-1}\left(a+\bar{a}-c_{T_{r}}-2 b_{11} d_{T_{r}, t-1}-b_{12} d_{O_{r}, t-1}\right) \\
\hat{d}_{O_{r}, t}=d_{O_{r}, t-1}+\beta d_{O_{r}, t-1}\left(a-c_{O_{r}}+\theta(\bar{\varphi}-\varphi)-b_{21} d_{T_{r}, t-1}-2 b_{22} d_{O_{r}, t-1}\right)(1-\varphi)
\end{array}\right.
$$

The parameters $\alpha, \beta(>0)$ in Equation (7) represent the two retailers' adjustment speed in each supply chain, respectively. The values of the adjustment speed $(\alpha, \beta)$ depend on the enthusiasm of the retailer's pursuit of profit, and their ability to regulate and control the sales. The retailer who has a strong drive to increase profits can take a bigger adjustment parameter and needs to have a stronger ability to regulate and control his sales.

\subsection{Demand Model}

In this paper, we consider the retailer sales volume is equal to the consumer demand for goods. $d_{t}$ is the whole demand of consumer $\left(d_{t}=d_{1, t}+d_{2, t}\right)$, and $q_{t}$ is the total orders of the two retailers $\left(q_{t}=q_{1, t}+q_{2, t}\right)$. 
Besides the retailers' sales game, the demand for one product is also affected by some incidental and random factors. Therefore, a demand model with random disturbance term is more representative of the actual supply chain:

$$
\left\{\begin{array}{l}
d_{T_{r}, t}=d_{T_{r}, t-1}+\alpha d_{T_{r}, t-1}\left(a+\bar{a}-c_{T_{r}}-2 b_{11} d_{T_{r}, t-1}-b_{12} d_{O_{r}, t-1}\right)+\tau \varepsilon_{1, t} \\
d_{O_{r}, t}=d_{O_{r}, t-1}+\beta d_{O_{r}, t-1}\left(a-c_{O_{r}}+\theta(\bar{\varphi}-\varphi)-b_{21} d_{T_{r}, t-1}-2 b_{22} d_{O_{r}, t-1}\right)(1-\varphi)+\tau \varepsilon_{2, t}
\end{array}\right.
$$

here, $\varepsilon_{i, t}$ is Gaussian white noise with zero mean and $\tau$ is intensity of the noise. System (8) is a nonlinear demand process with random disturbance which has much more complex nonlinear characteristics. Its complexity will be analyzed in Section 3.

\subsection{Order-Up-To Inventory Policy}

We assume that both retailers employ an order-up-to policy as their inventory policy. At the start of period $t$, retailer $i$ knows its own demand of period $t-1$ denoted by $d_{i, t-1}$, and must estimate the order-up-to point $S_{i, t}$, and send the order $q_{1, t}$ to the manufacturer. After the lead time $L_{i}$, Retailer $i$ receives the products from the manufacturer in the beginning of the period $t+L_{i}$. A retailer's expected inventory of the period $t$, is determined by the demand prediction of the lead time and the returned products:

$$
S_{i, t}=\hat{D}_{i, t}^{L_{i}}+z \hat{\sigma}_{i, t}^{L_{i}}
$$

where $\hat{\sigma}_{i, t}^{L_{i}}=\sqrt{\operatorname{Var}\left(D_{i, t}^{L_{i}}-\hat{D}_{i, t}^{L_{i}}\right)}$ represents the standard deviation between the actual demand and demand prediction of the lead time. $z(\geq 0)$ is called safety factor, on behalf of the expected level of service. If $z=0$, the retailer is risk neutral.

$R_{i, t}$ is the volume of returned products that the online retailer receives from consumers. The returned products are assumed to satisfy the conditions to be sold again without any other costs. The products meets the conditions will be returned to the online retailer, after a return cycle $L_{i}$ through its reverse logistics.

At the end of period $t-1$, the online retailer has gotten the information about the volume of the returned products in time $t$ :

$$
R_{i, t}=\varphi d_{i, t-L_{i}}
$$

Retailer $i$ can make its order $q_{i, t}$ based on the demand of period $t$ and the desired inventory goal, and then send the order to the manufacturer at the beginning of the period $t$. Retailer $i$ will receive the products at the start of period $t+L_{i}$. The order $q_{i, t}$ can be written as:

$$
q_{i, t}=S_{i, t}-S_{i, t-1}-R_{i, t}+d_{i, t-1}=\left(\hat{D}_{i, t}^{L_{i}}-\hat{D}_{i, t-1}^{L_{i}}\right)-R_{i, t}+z\left(\hat{\sigma}_{i, t}^{L}-\hat{\sigma}_{i, t-1}^{L}\right)+d_{i, t-1}
$$

In the beginning of the period $t$, Retailer $i$ knew the actual demands of consumers for its products $d_{i, t-1}$, but the actual demand of the lead time $d_{i, t}, d_{i, t+1}, \ldots, d_{i, t+L_{i}-1}$ are unknown, where $\hat{d}_{i, t}, \hat{d}_{i, t+1}$, $\ldots, \hat{d}_{i, t+L_{i}-1}$ are the corresponding predicted values for $d_{i, t}, d_{i, t+1}, \ldots, d_{i, t+L-1}$. The whole demand predictions of the lead time can be written as:

$$
\hat{D}_{i, t}^{L}=\hat{d}_{i, t}+\hat{d}_{i, t+1}+\cdots+\hat{d}_{i, t+L-1}
$$

On the basis of the assumption that the retailers use the bounded rationality to estimate $\hat{d}_{i, t}$ according to the demand observations from the previous period. The demand prediction in the lead time can be written as:

$$
\hat{D}_{i, t}^{L}=L_{i} \hat{d}_{i, t}
$$


Substituting Equation (12) into (10), then we can get the orders of the two retailers:

$$
\left\{\begin{array}{c}
q_{T_{r}, t}=L_{T_{r}}\left(\alpha d_{T_{r}, t-1}\left(a+\bar{a}-c_{T_{r}}-2 b_{11} d_{T_{r}, t-1}-b_{12} d_{O_{r}, t-1}\right)-\hat{d}_{T_{r}, t-1}\right) \\
+\left(L_{T_{r}}+1\right) d_{T_{r}, t-1}+z\left(\hat{\sigma}_{T_{r}, t}^{L}-\hat{\sigma}_{T_{r}, t-1}^{L}\right) \\
q_{O_{r}, t}=L_{O_{r}}\left(\beta d_{O_{r}, t-1}\left(a-c_{O_{r}}+\theta(\bar{\varphi}-\varphi)-b_{21} d_{T_{r}, t-1}-2 b_{22} d_{O_{r}, t-1}\right)(1-\varphi)-\hat{d}_{O_{r}, t-1}\right) \\
-R_{O_{r}, t}+\left(L_{O_{r}}+1\right) d_{O_{r}, t-1}+z\left(\hat{\sigma}_{O_{r}, t}^{L}-\hat{\sigma}_{O_{r}, t-1}^{L}\right)
\end{array}\right.
$$

\section{Complexity Analysis of the Demand System}

The nonlinear demand process with random disturbance shown in Equation (8) consists of a deterministic system and random items. When an attractor is disturbed by noises, the trajectories will deviate from this attractor temporarily, but most of them can be attracted back and form a cloud or bundle around the deterministic attractor, which is called stochastic attractor (Bashkirtseva and Ryashko [29]). For systems perturbed by weak noises, the response can be seen as stochastic attractors around the deterministic attractors and transitions between them (Guo et al. [30]). If $\tau$ is small enough compared with the value of $d_{i}$, the disturbance from the white noise doesn't change the properties completely. The time-consuming direct numerical simulation is a basic tool for analyzing the effects of small random perturbations in the stochastic dynamics (Bashkirtseva and Ryashko [31]).

In this paper, we investigate a nonlinear demand process with weak random disturbance. In the following subsection, we study the equilibrium and the local stability of the deterministic system firstly, and then analyze the complexity of the demand model.

\subsection{Equilibrium and the Local Stability}

Definition 1. (Equilibrium Point). An equilibrium point of the difference system $d_{i, t+1}=f\left(d_{i, t}\right)$, is $\left(d_{1}^{*}, d_{2}^{*}\right)$ such that $d_{i}^{*}=f\left(d_{i}^{*}\right)(i=1,2)$, (Galor [32]).

Definition 2. (Nash Equilibrium Point). An equilibrium point $\left(d_{1}^{*}, d_{2}^{*}\right)$ is a Nash equilibrium point of the difference system, if no retailer has anything to gain by changing only his or her own strategy.

There are four equilibrium points in the deterministic system of Equation (8):

$$
\begin{gathered}
E_{0}(0,0), E_{1}\left(\frac{a+\bar{a}-c_{T_{r}}}{2 b_{11}}, 0\right), E_{2}\left(0, \frac{a-c_{O_{r}}+\theta(\bar{\varphi}-\varphi)}{2 b_{22}}\right) \\
E^{*}\left(\frac{b_{12}\left(a-c_{O_{r}}+\theta(\bar{\varphi}-\varphi)\right)-2 b_{22}\left(a+\bar{a}-c_{T_{r}}\right)}{b_{12} b_{21}-4 b_{11} b_{22}}, \frac{b_{21}\left(a+\bar{a}-c_{T_{r}}\right)-2 b_{11}\left(a-c_{O_{r}}+\theta(\bar{\varphi}-\varphi)\right)}{b_{12} b_{21}-4 b_{11} b_{22}}\right)
\end{gathered}
$$

where $E_{0}, E_{1}, E_{2}$ are boundary equilibrium points, only $E^{*}$ is the Nash equilibrium point.

Proposition 1. In the deterministic system of Equation (8), the boundary equilibrium point $E_{0}, E_{1}$ and $E_{2}$ are not stable.

Proof. See Appendix A.

At the equilibrium point $E^{*}$, the Jacobian matrix has the form:

$$
J\left(E^{*}\right)=j_{0}\left[\begin{array}{ll}
j_{11} & j_{12} \\
j_{21} & j_{22}
\end{array}\right]
$$

here, $j_{0}=1 /\left(b_{12} b_{21}-4 b_{11} b_{22}\right), j_{11}=4 b_{11} b_{22}\left(-1+\alpha\left(a+\bar{a}-c_{T_{r}}\right)\right)+b_{12}\left(b_{21}-2 b_{11} \alpha\left(a-c_{O_{r}}+\right.\right.$ $\theta(\bar{\varphi}-\varphi))), j_{12}=b_{12} \alpha\left(2 b_{22}\left(a+\bar{a}-c_{T_{r}}\right)-b_{12}\left(a-c_{O_{r}}+\theta(\bar{\varphi}-\varphi)\right)\right), j_{21}=b_{21} \beta(-1+\varphi)\left(b_{21}\left(a+\bar{a}-c_{T_{r}}\right)\right.$ 
$\left.-b_{21} \mathcal{c}_{T_{r}}-2 b_{11}\left(a-c_{O_{r}}+\theta(\bar{\varphi}-\varphi)\right)\right), j_{22}=j_{0}+b_{21} \beta(-1+\varphi)\left(b_{21}\left(a+\bar{a}-c_{T_{r}}\right)-2 b_{11}\left(a-c_{O_{r}}+\theta(\bar{\varphi}-\varphi)\right)\right)$. In order to guarantee the sales at the equilibrium point are positive, we can set: $b_{12} b_{21}-4 b_{11} b_{22}<0$.

From the reality of the social economic activity perspective, the Nash equilibrium point $E^{*}$ is more meaningful. At this point the two retailers' sales volumes are not equal to zero. We can derive the sufficient and necessary condition for the stability by means of the Jury criterion:

$$
\left\{\begin{array}{c}
1+\operatorname{Tr}\left(J\left(E^{*}\right)\right)+\operatorname{Det}\left(J\left(E^{*}\right)\right)>0 \\
1-\operatorname{Tr}\left(J\left(E^{*}\right)\right)+\operatorname{Det}\left(J\left(E^{*}\right)\right)>0 \\
1-\operatorname{Det}\left(J\left(E^{*}\right)\right)>0
\end{array}\right.
$$

In order to obtain a better understanding of the stability characteristics of the system, we assign fixed values to the parameters. Unless otherwise specified, the parameter values will be still used in the following article. Without loss of generality, we set the parameters for $c_{O_{r}}=0.2, c_{T_{r}}=0.2, a=1$, $\bar{a}=0.1, b_{11}=1.1, b_{22}=1, b_{12}=0.25, b_{21}=0.3, \bar{\varphi}=0.05, \varphi=0.07$. At this moment, the stability region of the deterministic system of Equation (8) is shown as the green part in Figure 2a. The stability region of system is determined by both retailers' adjustment speed parameter. For both retailers, when the speed of the sales adjustment is in the stable region, the system tends to a Nash equilibrium point after a finite game; otherwise, the system is unstable.

Figure $2 \mathrm{~b}$ shows the basin of attraction in a stable system. The $x$-axis represents the traditional retailer's sales game decision and the $y$-axis represents the sales decision of the online retailer. The initial decision variables in the domain of attraction will converge to the same equilibrium point called an attractor. Here, the equilibrium attractor is $E^{*}=(0.37,0.34)$.

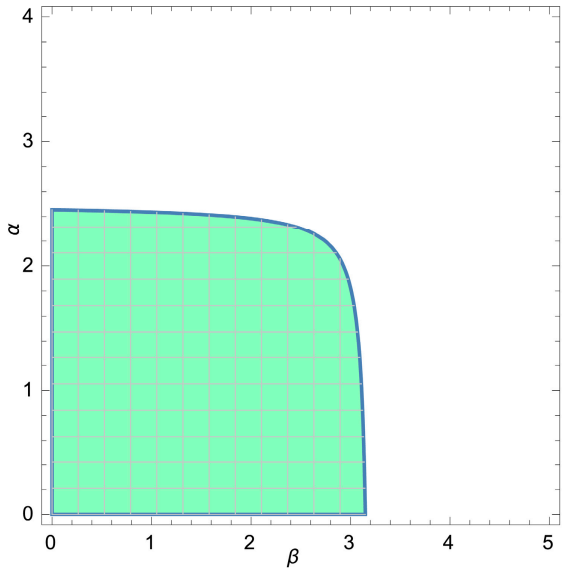

(a)

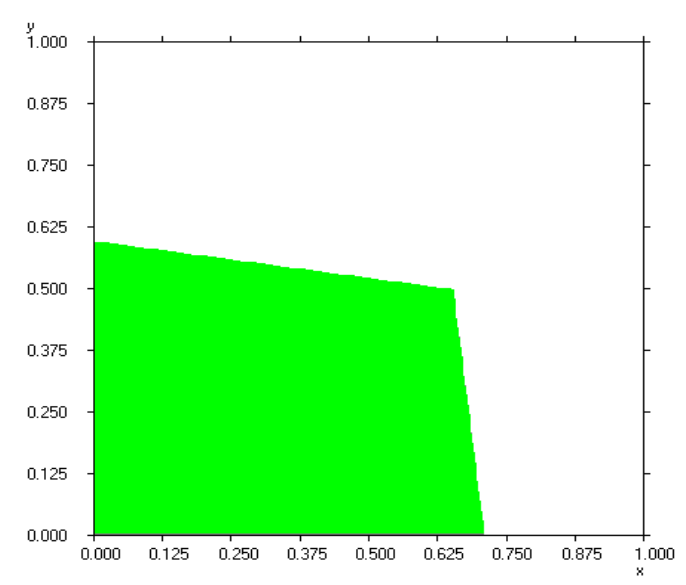

(b)

Figure 2. (a) Stability region; and (b) basin of attraction of system.

This means that the stable system is not sensitive to the initial decision values taken from the domain of attraction. However, not every initial sales volume can converge to that equilibrium point. Once the decision variables aren't in the basin of attraction, the systems will not converge. Therefore, both retailers should be mindful of the initial sales volume and avoid making sales out of the green area to maintain the market stability.

\subsection{Complexity of the Demand Model}

In this subsection, we investigate the complexity of the demand system with weak noises. Disturbed by weak noises, the stable, periodic and chaotic states of the deterministic system of Equation (8) will evolve into the quasi-stable, quasi-periodic and quasi-chaotic states. We may investigate the properties of the demand model with the help of the deterministic system of Equation (8). Firstly, we want to find the impact of both retailers' sales adjustment speeds on the system. 
Figure 3 shows parameter basin of the deterministic system of Equation (8), in which different colors represent different states. Besides the green stable state, the yellow area is cycles of period 2, purple for period 4, gray for chaos, and white for divergence. With the growth of $\alpha$ and $\beta$, green, yellow, red and purple constitute the road from period doubling bifurcation to chaos. In the discrete system, it is also known as the flip bifurcation. It is worth noting that there are also some intermittent odd periodic points in the chaotic region of the deterministic system of Equation (8), and we call them topological chaos. In Figure 3, we can find that there are two roads leading to the chaos:

1. When the adjustment speed of sales for retailers pass from the green area, sequentially through the yellow, red and purple areas to the gray area, the system enters into a chaotic state through the flip bifurcation. In the state of chaos, if retailers continue to increase the speed of adjustment, the system will overflow, which means one retailer will withdraw from the market.

2. When the adjustment speed of sales for retailers from the green area sequentially pass the yellow and red area to the gray area, the system from 4 cycle period enters into a chaotic state through the Neimark-Sacker bifurcation.

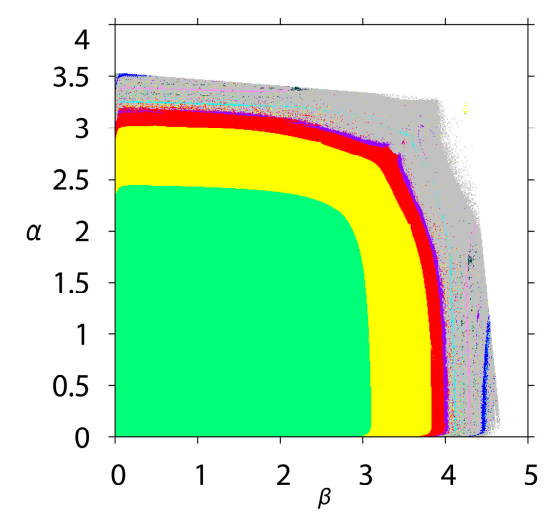

Figure 3. Parameter basin.

Secondly, we investigate the change of two retailers' sales volumes with respect to the adjustment speed parameter of online retailer via the bifurcation of the deterministic system. Figure 4 shows the bifurcation diagram of the deterministic system with $\alpha=1.5$ and $\beta$ varying from 2.7 to 4.3 . The small window in Figure 4 shows the whole bifurcation diagram when $\beta \in(0,4.3)$. The red line is the sales volume of the online retailer and the blue line represents that of the traditional retailer. As shown in the diagram, when the value of $\beta$ is less than 3.03, the sales volumes of both retailers are stable and the traditional retailer sells much more products than the online retailer. Once the adjustment speed of the online retailer grows larger than 3.03, the system experiences the bifurcation and enters into the two-period state. After four-period and eight-period, the system will finally fall into chaos. Apparently, the online retailer will be affected much more by the growth of $\beta$ and the vibration amplitude of its sales volume is more than that of the traditional retailer.

In the following section, we investigate the complexity of the system (8) considering the weak noise with the help of the largest Lyapunov exponent (LLE). The $L L E$ is an effective means for determining and classifying nonlinear system behavior. If the $L L E$ is less than zero, the deterministic system is in a quasi-stable state. With the growth of the adjustment parameter, once the $L L E$ increases to zero, the system will lose its stability and enters into the stage of quasi-periodic bifurcation if the LLE becomes negative again. But if the $L L E$ becomes positive after a zero value, the system will enter into chaos. Therefore, we can depend on the LLE diagram to determine the state of the demand model (quasi-stable, quasi-periodic, and quasi-chaotic).

When the noise intensity $\tau$ is set to 0.001 , we can plot the quasi-bifurcation diagram of the demand model and $L L E$ of system (7) in a figure. Figure $5 \mathrm{a}, \mathrm{b}$ give the quasi-bifurcation diagram and 
the corresponding $L L E$, with $\alpha=1.5$ and $\beta$ from 0 to 4.5. As shown in the figures, the LLE is less than zero when $\beta<3.03$. Therefore, the deterministic system of Equation (8) is in the stable state. However, system (8) is in a quasi-stable state rather than a pure stable state, i.e., the sales volumes of retailers are not determined at fixed values and fluctuate around their equilibriums slightly. The same phenomenon occurs in the period-doubling bifurcation stage, and the system is more chaotic in the quasi-chaos state.

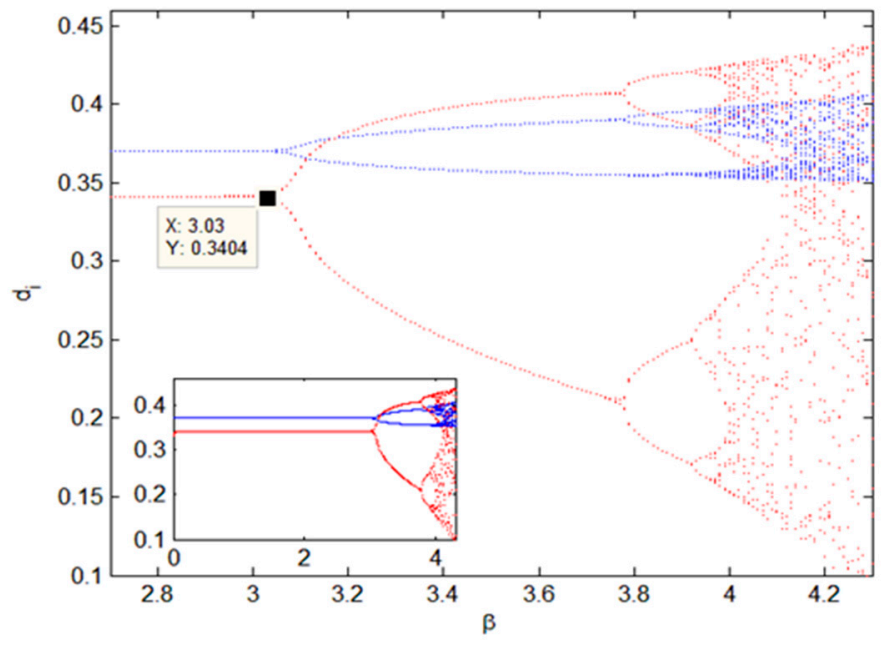

Figure 4. Bifurcation diagram of the deterministic system.

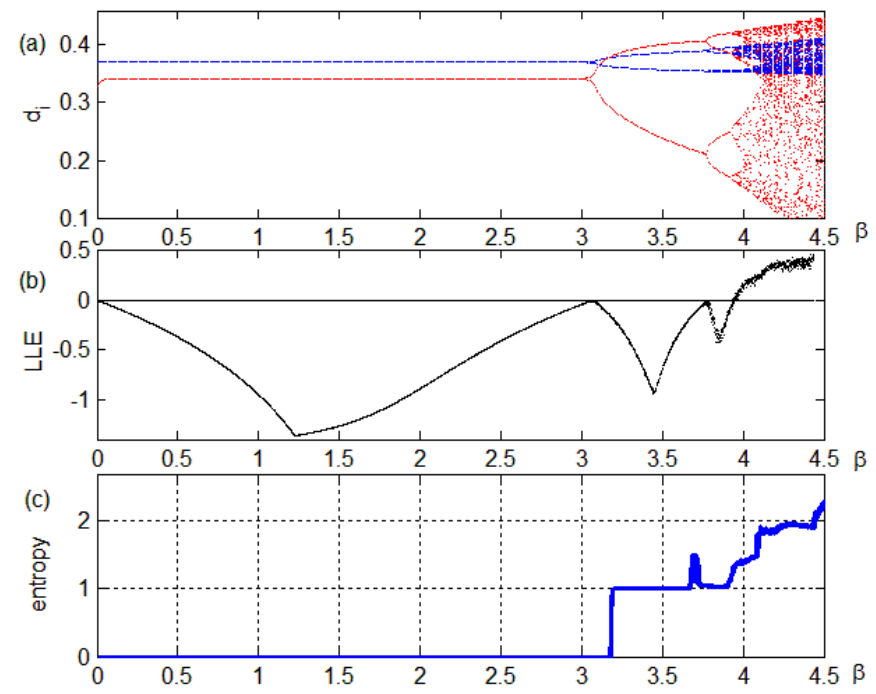

Figure 5. (a) Quasi-bifurcation; (b) Largest Lyapunov exponent; and (c) Entropy diagram.

According to the theory of entropy (Han et al. [33]), we plot the entropy diagram to show the complexity of the system. Figure $5 c$ gives the entropy diagram of the sales volume for the online retailer as $\beta$ varying from 0 to 4.5 . Combining this with Figure $5 \mathrm{~b}$, we can find that the entropy is equal to zero when system is in the quasi-stable state $(\beta<3.03)$, simultaneously, the $L L E$ is less than zero. Once the system enters into a period-doubling bifurcation stage or the quasi-chaos state $(\beta>3.03)$, the entropy will be positive. The larger the entropy is, the more chaotic the system is.

Next, we study the complexity with the help of the system's attractor. Figure 6 shows attractors of system ( 8 ) and its deterministic system when $\beta=4.15$. In Figure $6 a$, the blue line is the chaos attractor of the deterministic system, while the red points around the blue line is a quasi-chaos attractor with weak noise in Figure 6b. 


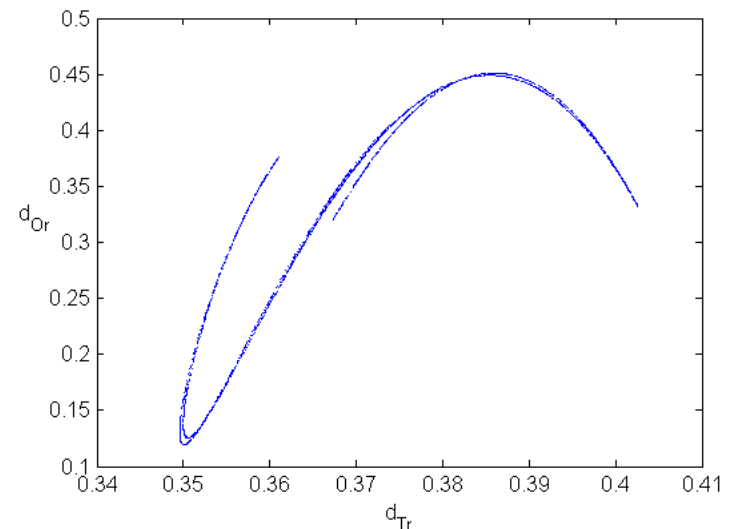

(a)

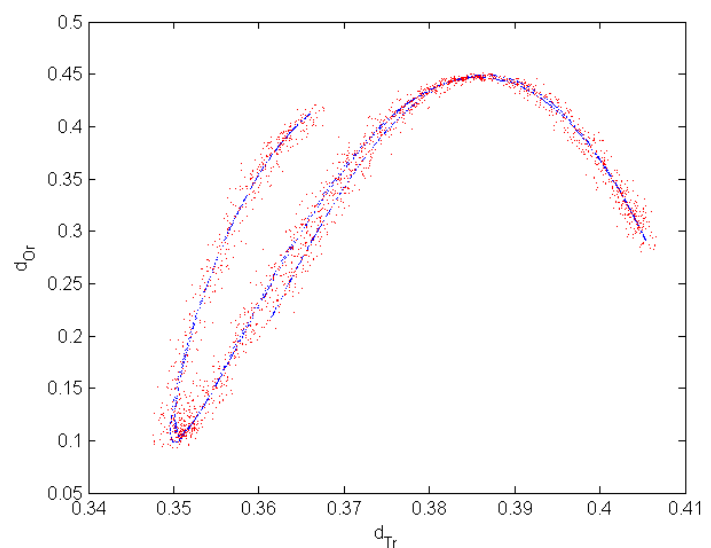

(b)

Figure 6. (a) The attractor of the deterministic system; and (b) the quasi-chaos attractor of the system with weak noise.

\subsection{Impact of the Return Rate}

In this subsection, the profits of two retailers will be analyzed in the stable state. The optimal sales volumes and profits of retailers can be derived via the first-order optimal condition.

The optimal sales volumes can be expressed as:

$$
\left\{\begin{array}{l}
d_{T_{r}}^{*}=\frac{b_{12}\left(a-c_{O_{r}}+\theta(\bar{\varphi}-\varphi)\right)-2 b_{2_{22}}\left(a+\bar{a}-c_{T_{r}}\right)}{b_{12} b_{21}-4 b_{11} b_{22}} \\
d_{O_{r}}^{*}=\frac{b_{21}\left(a+\bar{a}-c_{T_{r}}\right)-2 b_{11}\left(a-c_{O_{r}}+\theta(\bar{\varphi}-\varphi)\right)}{b_{12} b_{21}-4 b_{11} b_{22}}
\end{array}\right.
$$

Substituting Equation (16) into Equations (3) and (4), the optimal profits of two retailers can be derived:

$$
\left\{\begin{array}{c}
\pi_{T_{r}}^{*}=\frac{b_{11}\left(b_{12}\left(a-c_{O_{r}}+\theta(\bar{\varphi}-\varphi)\right)-2 b_{22}\left(a+\bar{a}-c_{T_{r}}\right)\right)^{2}}{\left(b_{12} b_{21}-4 b_{11} b_{22}\right)^{2}} \\
\pi_{O_{r}}^{*}=\frac{b_{22}(1-\varphi)\left(b_{21}\left(a+\bar{a}-c_{T_{r}}\right)-2 b_{11}\left(a-c_{O_{r}}+\theta(\bar{\varphi}-\varphi)\right)\right)^{2}}{\left(b_{12} b_{21}-4 b_{11} b_{22}\right)^{2}}
\end{array}\right.
$$

Proposition 2. When the online retailer employs a return policy, the sales of the traditional retailer increase, but those of the online retailer will be reduced by the growth of the return rate in the online channel. The optimal sales volume in the online channel will be affected by its return rate much more than that of a traditional retailer.

Proof. See Appendix B.

Proposition 3. When the online retailer employs a return policy, the profits of the traditional retailer and the online retailer are both decreasing functions with respect to the return rate.

Proof. See Appendix C.

Based on the above parameter hypothesis, a numerical simulation is proposed to investigate the impact of the return rate on profits. Figure 7 shows how the two retailers' optimal profits are affected by the return rate. The red line is the profit of the online retailer and that blue line is that of the traditional retailer. It is clear that the profit of the online retailer will be reduced as the return rate grows. However, it is interesting that the profit of the traditional retailer will be reduced by the growth of the online retailer's return rate. 


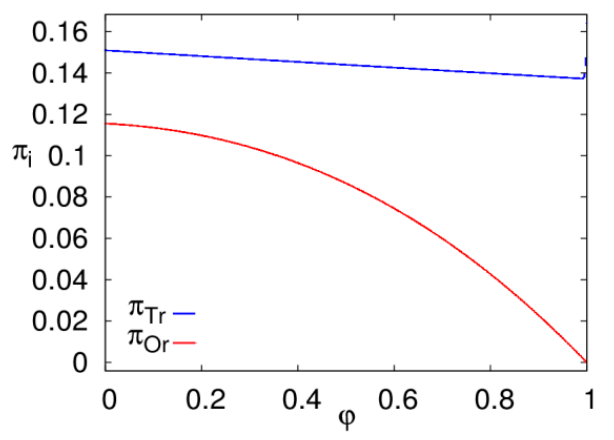

Figure 7. The optimal profits with respect to the return rate.

\section{Analysis of Bullwhip Effect}

From the above analysis, we can find with the continuous growth of the sales adjustment speed of retailers, demand model enters into the quasi-periodic state from the quasi-stable state, and finally evolves into the quasi-chaotic state. In this section, we will design experiments to investigate the bullwhip effect, when the demand model is quasi-stable, quasi-periodic, and quasi-chaotic.

\subsection{Measure of Bullwhip Effect}

This experiment mainly inspects the order variance ratio (bullwhip effect). We take the common measure proposed by Chen et al. [12,13].

Order variance ratio $(O V R)$ :

$$
O V R=\frac{\sigma_{q}^{2} / \mu_{q}}{\sigma_{d}^{2} / \mu_{d}}
$$

We also set the parameters in the inventory policy and the demand prediction for the following experiments. Considering the online retailer has got the products sooner the traditional retailer, We let lead time $L_{O_{r}}=2$ and $L_{T_{r}}=3$, and the whole time length $T=52$ for every numerical simulation. Experiments 1 and 2 investigate how bullwhip effect is affected by the risk neutral retailers' sales game strategies.

\subsection{Experiment 1: To Investigate the Dynamical Evolution of Bullwhip Effect over Time}

We design to calculate and compare the order variance ratio of each cycle $(T=52)$ when the system is in the different state. As can be seen from Figure 5, when $\alpha=1.5$, for the online retailer, with the increasing of the sales adjustment speed $\beta$, system (8) from the quasi-stable, quasi-period enters into quasi-chaos. We set three different $\beta$ values, respectively, making the system (8) be in a quasi-stable, quasi-periodic and quasi-chaotic state, as follows: (1) Quasi-stable state: $\beta=1.5$; (2) Quasi-periodic state: $\beta=3.5$; (3) Quasi-chaos state: $\beta=4.15$.

In the three different states, we can find some properties by calculating the order variance ratio. Figure 8a gives the order variance ratio diagram of the traditional retailer when the system is in the quasi-stable, quasi-periodic or quasi-chaotic states, respectively. The small window in the north-east corner of Figure 8a is the whole diagram, while the big figure is a magnified image when $O V R \in[0,5]$. In the quasi-stable state, with the passage of time, the order variance ratio will decrease rapidly close to 1 during the first ten periods, and be stable at 1 in the time later. While in the quasi-periodic and quasi-chaotic state, the order variance ratio will gradually increase after a rapid reduction, since time $t=10$. Figure $8 \mathrm{~b}$ gives the order variance ratio diagram of the online retailer when the system is in the quasi-stable, quasi-periodic or quasi-chaotic states. The small window in the north-east corner of Figure $8 \mathrm{~b}$ is the whole diagram, while the big figure is a magnified image when $O V R \in[0,12]$. There is the similar trend for the $O V R$ of the online retailer in the quasi-stable state. Unlike the traditional retailer, the $O V R$ of the online retailer is greater in the quasi-periodic and quasi-chaotic 
states. After time $t=17$, the $O V R$ of the online retailer in the quasi-periodic state is larger than that in quasi-chaotic state.

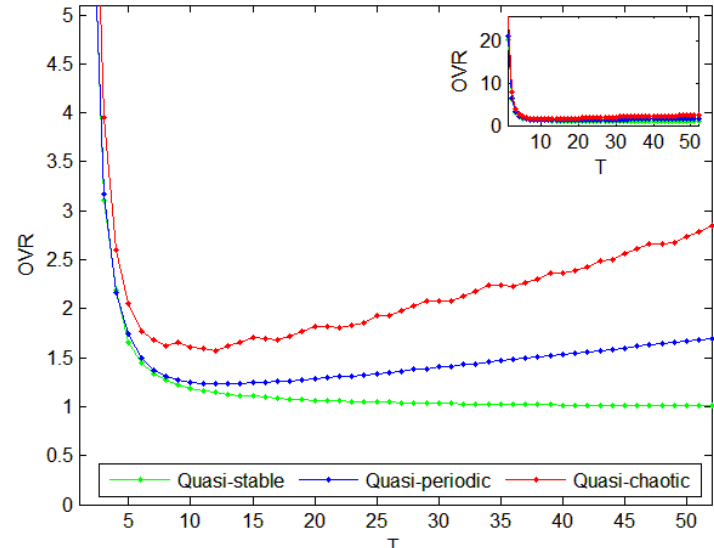

(a)

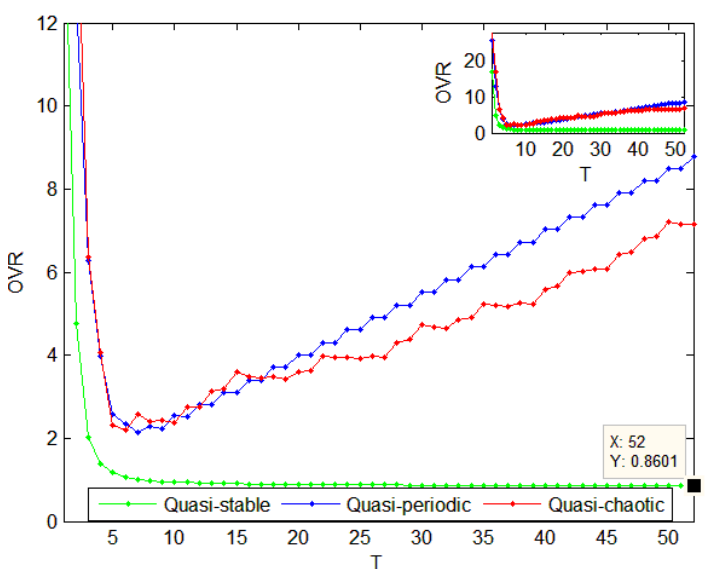

(b)

Figure 8. (a) Timing diagram of the traditional retailer's bullwhip effect; (b) Timing diagram of the online retailer's bullwhip effect.

\subsection{Experiment 2: To Investigate the Impact of the Sales Adjustment Speed on the Bullwhip Effect}

We design to calculate the order variance ratio of the total 52 cycles and investigate the changes of the $O V R$ as the sales adjustment speed of the online retailer changes. In order to further study how the adjustment speed of sales volume for retailers affects the bullwhip effect, we set $\alpha=1.5$, and make $\beta$ increase. We turn to observe the change trends of bullwhip effect in the process of system evolution for two different retailers.

Figure 9a gives the influence of adjustment speed on the bullwhip effect for the traditional retailer. From the figure, we can find that when the online retailer begins to adopt an adjustment mechanism in a quasi-stable state, there is a little bullwhip effect from the traditional retailer's orders when $\beta<1$.6. There is no bullwhip effect when $1.6<\beta<3$. When system (8) is beginning to enter into a quasi-periodic state, the bullwhip effect appears and increases rapidly, with some waving phenomena. Bullwhip effect will be in the high turbulence when the system is in a quasi-chaotic state.

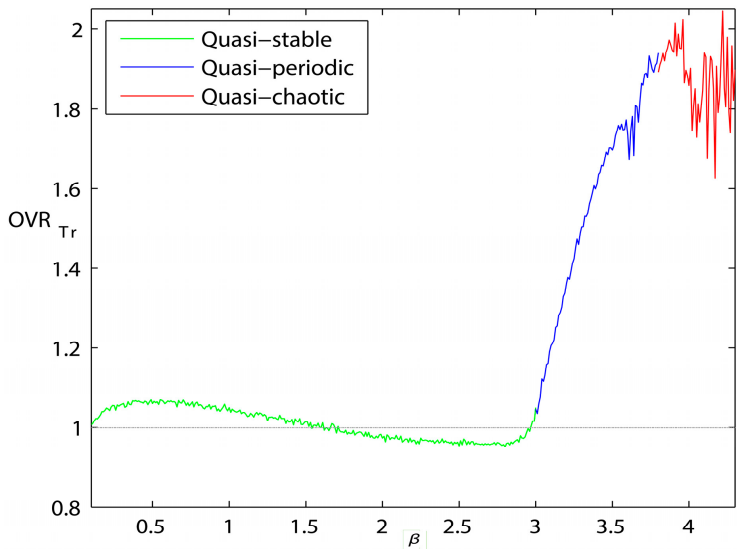

(a)

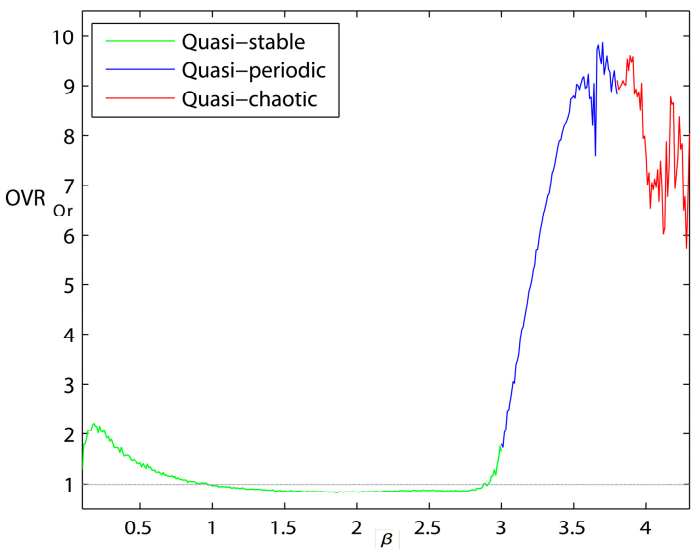

(b)

Figure 9. (a) Effect of $\beta$ on the traditional retailer's OVR; (b) Effect of $\beta$ on the online retailer's OVR.

As shown in Figure 9b, the order variance ratio will show a similar trend to that of the traditional retailer when the online retailer adopts an adjustment mechanism. There is a little bullwhip effect 
from the online retailer's orders when $\beta<0.94$ and no bullwhip effect when $0.94<\beta<2$.9. There is a rapid increase once $\beta>2.9$, with a high turbulence in a quasi-chaotic state.

Through the comparison of the two maps, we find that both retailers will suffer little bullwhip effect when the system is in the quasi-stable state. Bullwhip effect can be mitigated completely for the two retailers when $1.6<\beta<2$.9. The largest $O V R$ of the traditional retailer is less than 2 , while the $O V R$ of the online retailer is larger than 2 in the vast majority of cases when the system is in a quasi-periodic state or a quasi-chaotic state. This system instability caused by the online retailer has a greater impact on itself, leading to greater bullwhip effect in its own channel.

\section{Chaos Control and Mitigation of Bullwhip Effect}

The above simulations suggest that the retailers' sales adjustment speeds in the quasi-stable state would bring less bullwhip effect than the quasi-period doubling and quasi-chaotic states. From the supply management perspective, to keep the system away from chaos and weaken the bullwhip effect are helpful for the retailers and the manufacturer. Therefore, it is important to find a useful method of chaos control. Some literatures in the field of supply chain complexity have successfully used the delayed feedback control method to control the chaos of supply chain system [34,35].

Definition 3. (The Delayed Feedback Control (DFC) Method). For a general chaotic system with an additional feedback force:

$$
x(t)=B x(t-1)+f(x(t-1))+u(t)
$$

where $x(t) \in R^{n}$ is the state vector, $u(t)$ is feedback control input vector, $B$ is constant system matrix representing the linear parts of the system, $f$ is the nonlinear parts of the system. If the control input is presented as $u(t)=K(x(t-\Delta T)-x(t))$, the method is called the delayed feedback control method, where $\Delta T$ is the length of the lag time, $K$ is the control parameter (Guan [36]).

We make the online retailer control the chaos when making decisions on the sales with the help of the control parameter $K$. With the controlling, the sales (demands) of the online retailer can be rewritten as:

$$
\begin{gathered}
d_{O_{r}, t}=\beta d_{O_{r}, t-1}\left(a-c_{O_{r}}+\theta(\bar{\varphi}-\varphi)-b_{21} d_{T_{r}, t-1}-2 b_{22} d_{O_{r}, t-1}\right)(1-\varphi)+d_{O_{r}, t-1} \\
+K\left(d_{O_{r}, t-\Delta T}-d_{O_{r}, t}\right)+\tau \varepsilon_{O_{r}, t}
\end{gathered}
$$

We consider the control parameter in the system with $\Delta T=1$, and then we can obtain a new sales demand game system for the two retailers of the supply chain, under the control of the online retailer:

$$
\left\{\begin{array}{c}
d_{T_{r}, t}=\alpha d_{T_{r}, t-1}\left(a+\bar{a}-c_{T_{r}}-2 b_{11} d_{T_{r}, t-1}-b_{12} d_{O_{r}, t-1}\right)+d_{T_{r}, t-1}+\tau \varepsilon_{T_{r}, t} \\
d_{O_{r}, t}=\beta d_{O_{r}, t-1}\left(a-c_{O_{r}}+\theta(\bar{\varphi}-\varphi)-b_{21} d_{T_{r}, t-1}-2 b_{22} d_{O_{r}, t-1}\right)(1-\varphi) \\
+d_{O_{r}, t-1}+K\left(d_{O_{r}, t-1}-d_{O_{r}, t}\right)+\tau \varepsilon_{O_{r}, t}
\end{array}\right.
$$

First, we make the control parameter $K=0.5$ and the adjustment parameter $\alpha=1.5$ to investigate the effect of the DFC method. Figure 10a shows the demands quasi-bifurcation diagram of the two retailers as the adjustment parameter $\beta$ increasing from 4 to 6.5. The small window in Figure 10a shows the whole bifurcation diagram when $\beta \in(0,6.5)$. We can see that the quasi-stable state is extended due to the feedback parameter $(K=0.5)$. Figure $11 \mathrm{~b}$ shows the bullwhip effect of the online retailer as the sales adjustment speed $\beta$ varies from 0 to 6.5 . We can see that the period with little bullwhip effect is extended obviously. 


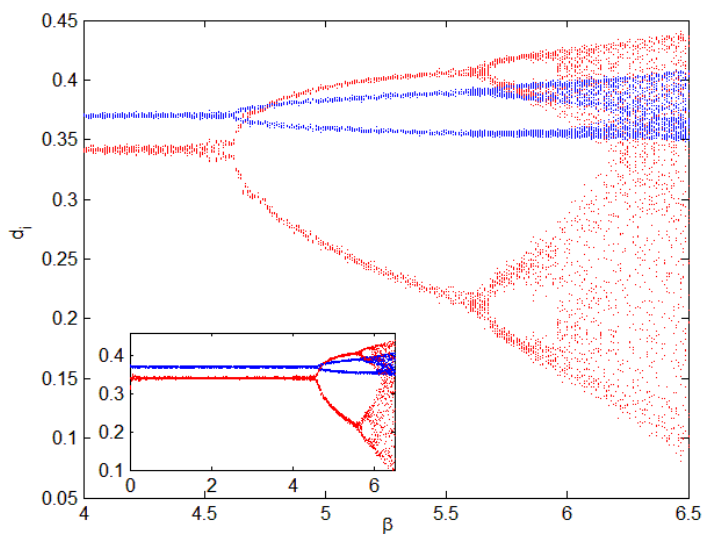

(a)

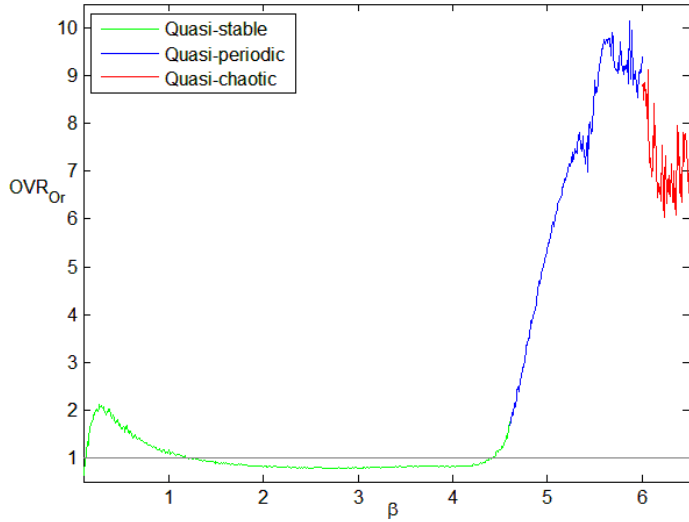

(b)

Figure 10. (a) Quasi-bifurcation diagram; and (b) the online retailer's bullwhip effect with $K=0.5$, $\alpha=1.5$ and $\beta \in[0,6.5]$.

Secondly, we observe the control process of the system and the bullwhip effect, when the adjustment parameters $\alpha=1.5$ and $\beta=4.15$. According to the previous numerical simulation and analysis, we know that in this case the system is in a state of chaos. Next we will observe the bifurcation diagram and bullwhip effect of the online retailer in the controlled system after entering the control parameter $K$.

Based on the numerical simulation results, we can find that the system $(\alpha=1.5, \beta=4.15)$ is in a quasi-chaotic state and the system is gradually changed from quasi-chaos to quasi-stable state under the action of the DFC parameter $K$.

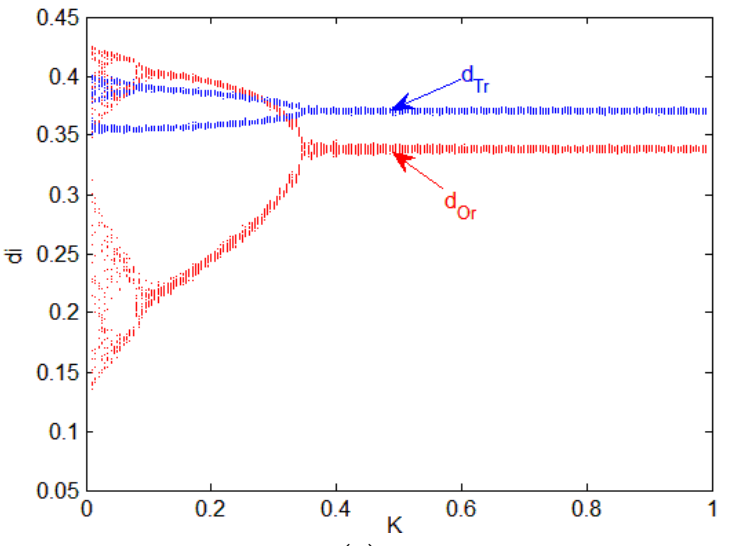

(a)

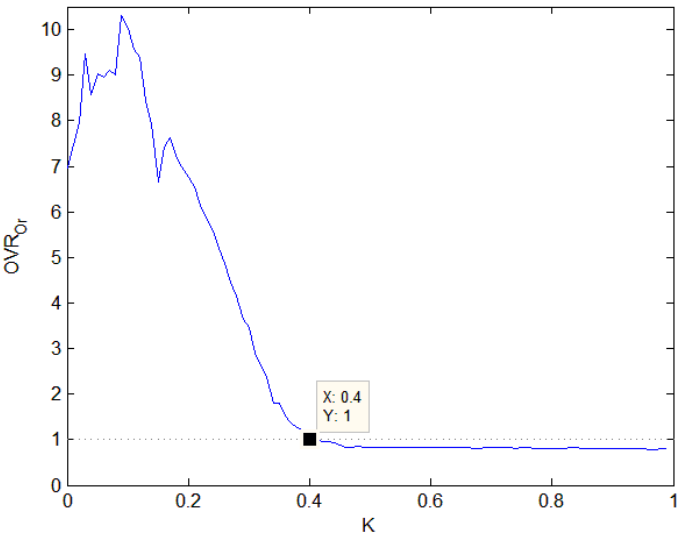

(b)

Figure 11. (a) Quasi-bifurcation diagram; and (b) the online retailer's bullwhip effect with $\alpha=1.5$ and $\beta=4.15, K \in(0,1)$.

From Figure 11a, we can see that when $K>0.13$, the system is in a quasi-two-fold period state; when $K>0.4$, the competition system is out of chaos and enters into a quasi-stable state. Figure $11 \mathrm{~b}$ shows the impact of the control parameter $K$ on $O V R$. As the control parameter grows from zero, the $O V R$ of the online retailer remains high and volatile until $K>0.2$. There is a rapid descent of $O V R$ when the control parameter is in the interval $[0.2,0.4]$, especially, $O V R$ is equal to one when $K=0.4$, and less than one when $K>0.4$, i.e., the bullwhip effect is mitigated thanks to $K$.

The effect of the control parameter can also be found in Figure 12. As the growth of $K$, the entropy of the online retailer will decrease significantly until near to 0.4 , then it will be stable at zero. 
The entropy characters of Figure 12 are consistent with the quasi-bifurcation diagram and bullwhip effect in Figure 11.

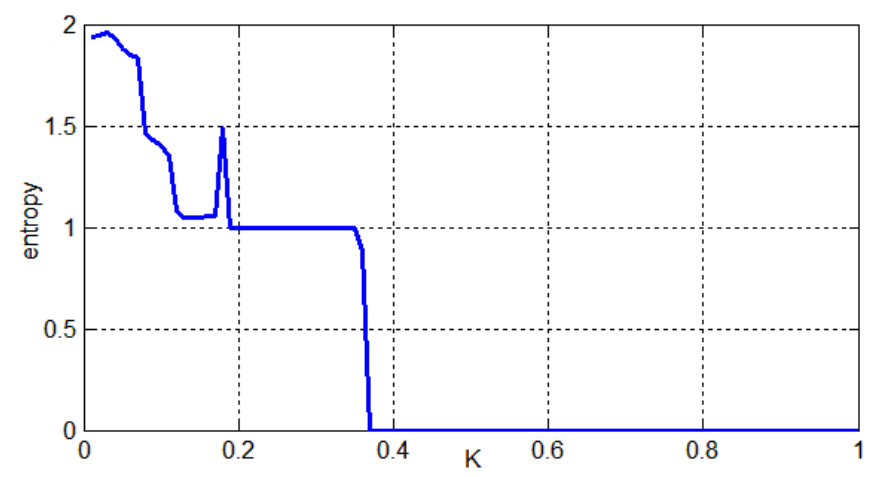

Figure 12. Entropy diagram of the online retailer with $\alpha=1.5$ and $\beta=4.15, K \in(0,1)$.

This shows that the DFC method has achieved a good effect, and effectively alleviated the supply chain bullwhip effect and entropy under a sales game demand model.

\section{Conclusions}

This paper constructs a supply chain model with a manufacturer and two retailers. In the sales game process, retailers forecast their sales volume based on their bounded rationality and information and replenish goods using the order-up-to inventory policy. We find the demand game system disturbed by weak noise will experience quasi-stable, quasi-periodic and quasi-chaotic state as retailers increase their sales adjustment speeds. This paper mainly analyzes these nonlinear characteristics of the supply chain with consumer returns under a sales game scenario and compares the bullwhip effect under different iteration states. The conclusions show that: the profit of the traditional retailer will be reduced with the growth of the online retailer's return rate. As the online retailer's adjusting parameter increase, the system enters a quasi-periodic state, and the bullwhip effect of both retailers increases rapidly with a slight shock. The bullwhip effect experiences intense shock when the system enters a quasi-chaotic state. The supply chain system suffers a great bullwhip effect in the quasi-periodic state and the quasi-chaotic state. For the online retailer, an adjustment parameter which maintains the system in the quasi-steady stage is an optimal sales adjustment strategy to make the supply chain avoid the greater bullwhip effect. With the help of the delayed feedback control method, the online retailer can control the system, expand the stable region and effectively mitigate the bullwhip effect.

There are a number of implications for the manufacturer and the retailers: (1) the manufacturer should help the online retailer maintain a low return rate, otherwise, the profit of the traditional retailer will be reduced, too; (2) the retailers can adopt a suitably large sales adjustment speed to obtain greater profits, but they must keep the sales game system in the stable state and their sales volume in the basin of attraction; (3) the manufacturer should pay attention to the adjustment speeds of the two retailers. Once the system falls in to chaos, the delayed feedback control method can be adopted to control the chaotic system far away from the large bullwhip effect and large entropy.

Limitations of this work include: (1) all the results are obtained from the simulations; (2) only one traditional retailer and one online retailer are considered in the supply chain model. The theoretical analysis of the bullwhip effect and multiple retailers in the game supply chain would be improvements and directions for future research.

Acknowledgments: The research was supported by the National Natural Science Foundation of China (71571131), and also supported by Doctoral Fund of Ministry of Education of China (grant No. 20130032110073). 
Author Contributions: Wandong Lou and Junhai Ma built the supply chain model; Junhai Ma provided economic interpretation; Wandong Lou performed mathematical derivation; Xueli Zhan carried out numerical simulation; they wrote this research manuscript together. All authors have read and approved the final manuscript.

Conflicts of Interest: The authors declare no conflict of interest.

\section{Appendix Proof for Proposition 1}

According to the stability theory: the local stability of the equilibrium point can be determined by the eigenvalues of the Jacobian matrix of the system, the Jacobian matrix of the deterministic system of Equation (8) is as follows:

$$
J(E)=\left[\begin{array}{cc}
1+\alpha\left(a+\bar{a}-c_{T_{r}}-4 b_{11} d_{T_{r}}-b_{12} d_{O_{r}}\right) & -b_{12} d_{T_{r}} \alpha \\
-b_{21} d_{O_{r}} \beta(1-\varphi) & 1+\beta(1-\varphi)\left(a-c_{O_{r}}+\theta(\bar{\varphi}-\varphi)-b_{21} d_{T_{r}}-4 b_{22} d_{O_{r}}\right)
\end{array}\right]
$$

At $E_{0}$, the Jacobian matrix has the form:

$$
J\left(E_{0}\right)=\left[\begin{array}{cc}
1+\alpha\left(a+\bar{a}-c_{T_{r}}\right) & 0 \\
0 & 1+\beta(1-\varphi)\left(a-c_{O_{r}}+\theta(\bar{\varphi}-\varphi)\right)
\end{array}\right]
$$

The eigenvalues of this matrix are $\lambda_{1}=1+\alpha\left(a+\bar{a}-c_{T_{r}}\right)$ and $\lambda_{2}=1+$ $\beta(1-\varphi)\left(a-c_{O_{r}}+\theta(\bar{\varphi}-\varphi)\right)$. Since $\alpha, \beta>0$, when $c_{T_{r}}, c_{O_{r}}$ are less than their price ceiling, it is easy to see that $\lambda_{i}>1, i=1,2$, so that the boundary equilibrium point $E_{0}$ is the source, and not stable.

At $E_{1}$, the Jacobian matrix has the form:

$$
J\left(E_{1}\right)=\left[\begin{array}{cc}
1-\alpha\left(a+\bar{a}-c_{T_{r}}\right) & -\frac{b_{12}}{2 b_{11}}\left(a+\bar{a}-c_{T_{r}}\right) \alpha \\
0 & 1+\beta(1-\varphi)\left(a-c_{O_{r}}+\theta(\bar{\varphi}-\varphi)-\frac{b_{21}}{2 b_{11}}\left(a+\bar{a}-c_{T_{r}}\right)\right)
\end{array}\right]
$$

At the moment, the eigenvalues of this matrix are $\lambda_{1}=1-\alpha\left(a+\bar{a}-c_{T_{r}}\right)$ and $\lambda_{2}=1+$ $\beta(1-\varphi)\left(a-c_{O_{r}}+\theta(\bar{\varphi}-\varphi)-\frac{b_{21}}{2 b_{11}}\left(a+\bar{a}-c_{T_{r}}\right)\right)$. It is easy to see that $\lambda_{2}>1$, therefore, the boundary equilibrium point $E_{1}$ is unstable. We can also find $\lambda_{1}<1$, thus, we can determine $E_{1}$ is a saddle point.

At $E_{2}$, the Jacobian matrix has the form:

$$
J\left(E_{2}\right)=\left[\begin{array}{cc}
1+\alpha\left(a+\bar{a}-c_{T_{r}}-\frac{b_{12}}{2 b_{22}}\left(a-c_{O_{r}}+\theta(\bar{\varphi}-\varphi)\right)\right) & 0 \\
-\frac{b_{21}}{2 b_{22}} \beta(1-\varphi)\left(a-c_{O_{r}}+\theta(\bar{\varphi}-\varphi)\right) & 1-\beta(1-\varphi)\left(a-c_{O_{r}}+\theta(\bar{\varphi}-\varphi)\right)
\end{array}\right]
$$

The eigenvalues of this matrix are $\lambda_{1}=1+\alpha\left(a+\bar{a}-c_{T_{r}}-\frac{b_{12}}{2 b_{22}}\left(a-c_{O_{r}}+\theta(\bar{\varphi}-\varphi)\right)\right), \lambda_{2}=1-$ $\beta(1-\varphi)\left(a-c_{O_{r}}+\theta(\bar{\varphi}-\varphi)\right)$. There is $\lambda_{1}>1$, so the equilibrium point $E_{2}$ is unstable. It can be found that $\lambda_{2}<1$, so the boundary equilibrium $E_{2}$ is a saddle point of the deterministic system of Equation (8), too.

\section{Appendix Proof of Proposition 2}

The partial derivative of the sales volume with respect to the return rate can be derived via Equation (16):

$$
\begin{aligned}
\frac{\partial d_{T_{r}}^{*}}{\partial \varphi} & =-\frac{b_{12} \theta}{b_{12} b_{21}-4 b_{11} b_{22}} \\
\frac{\partial d_{O_{r}}^{*}}{\partial \varphi} & =\frac{2 b_{11} \theta}{b_{12} b_{21}-4 b_{11} b_{22}} .
\end{aligned}
$$


Considering $b_{12} b_{21}-4 b_{11} b_{22}\left\langle 0, b_{i j}\right\rangle 0$, and $\theta>0$, we can determine $\frac{\partial d_{T_{r}}^{*}}{\partial \varphi}>0$ and $\frac{\partial d_{O_{r}}^{*}}{\partial \varphi}<0$. Therefore, with respect to $\varphi, d_{\mathrm{T}_{\mathrm{r}}}^{*}$ is an increasing function, but $d_{O_{r}}^{*}$ is a decreasing function. It is obvious that $b_{11}>b_{12}$, so $\frac{\left|\partial_{\varphi} d_{O_{r}}^{*}\right|}{\left|\partial_{\varphi} d_{T_{r}}^{*}\right|}>2$ can be derived.

\section{Appendix Proof of Proposition 3}

The partial derivative of profits with respect to the return rate can be derived via Equation (21):

$$
\begin{gathered}
\frac{\partial \pi_{T_{r}}^{*}}{\partial \varphi}=\frac{2 b_{11} b_{12} \theta\left(b_{12}\left(a-c_{O_{r}}+\theta(\bar{\varphi}-\varphi)\right)-2 b_{22}\left(a+\bar{a}-c_{T_{r}}\right)\right)}{\left(b_{12} b_{21}-4 b_{11} b_{22}\right)^{2}} \\
\frac{\partial \pi_{O_{r}}^{*}}{\partial \varphi}=\frac{b_{22}\left(b_{21}\left(a+\bar{a}-c_{T_{r}}\right)-2 b_{11}\left(a-c_{O_{r}}+\theta(\bar{\varphi}-\varphi)\right)\right)\left(4 b_{11} \theta(1-\varphi)-b_{21}\left(a+\bar{a}-c_{T_{r}}\right)+2 b_{11}\left(a-c_{O_{r}}+\theta(\bar{\varphi}-\varphi)\right)\right)}{\left(b_{12} b_{21}-4 b_{11} b_{22}\right)^{2}}
\end{gathered}
$$

Considering the price gap between retailers' ceiling and difference between retailers' costs won't be too huge, $\frac{a+\bar{a}-c_{T_{r}}}{a-c_{O_{r}}+\theta(\bar{\varphi}-\varphi)}<2$. Because $b_{i j}<b_{i i}$, and $a>\max \left\{c_{T_{r}}, c_{O_{r}}\right\}$, then we can get $b_{i j}\left(a+\bar{a}-c_{T_{r}}\right)<2 b_{i i}\left(a-c_{O_{r}}+\theta(\bar{\varphi}-\varphi)\right),(i \neq j, i=1,2, j=1,2)$. Therefore, $\frac{\partial \pi_{T_{r}}^{*}}{\partial \varphi}<0$ and $\frac{\partial \pi_{O_{\mathrm{r}}}^{*}}{\partial \varphi}<0$.

\section{References}

1. CNNIC. 37th China Internet Development Statistics Report. Available online: http://www.cnnic.net.cn/ hlwfzyj/hlwxzbg/hlwtibg/201601/P020160122444930951954.pdf (accessed on 2 February 2017).

2. CNNIC. Chinese Online Shopping Market Research Report in 2015. Available online: http://www.cnnic.net. cn/hlwfzyj/hlwxzbg/dzswbg/201606/P020160721526975632273.pdf (accessed on 2 February 2017).

3. Lee, H.L.; Padmanabhan, V.; Whang, S. Information distortion in a supply chain: The bullwhip effect. Manag. Sci. 1997, 43, 546-558. [CrossRef]

4. Luong, H.T.; Phien, N.H. Measure of bullwhip effect in supply chains: The case of high order autoregressive demand process. Eur. J. Oper. Res. 2007, 183, 197-209. [CrossRef]

5. Gilbert, K. An ARIMA supply chain model. Manag. Sci. 2005, 51, 305-310. [CrossRef]

6. Duc, T.T.; Luong, H.T.; Kim, Y.D. A measure of bullwhip effect in supply chains with a mixed autoregressive-moving average demand process. Eur. J. Oper. Res. 2008, 187, 243-256. [CrossRef]

7. Gaalman, G.; Disney, S.M. On bullwhip in a family of order-up-to policies with ARMA $(2,2)$ demand and arbitrary lead-times. Int. J. Prod. Econ. 2009, 121, 454-463. [CrossRef]

8. Buchmeister, B.; Friscic, D.; Lalic, B.; Palcic, I. Analysis of a three-stage supply chain with level constraints. Int. J. Simul. Model. 2012, 11, 196-210. [CrossRef]

9. Nepal, B.; Murat, A.; Chinnam, R.B. The bullwhip effect in capacitated supply chains with consideration for product life-cycle aspects. Int. J. Prod. Econ. 2012, 136, 318-331. [CrossRef]

10. Nagaraja, C.H.; Thavaneswaran, A.; Appadoo, S.S. Measuring the bullwhip effect for supply chains with seasonal demand components. Eur. J. Oper. Res. 2015, 242, 445-454. [CrossRef]

11. Wang, X.; Disney, S.M. Mitigating variance amplification under stochastic lead-time: The proportional control approach. Eur. J. Oper. Res. 2017, 256, 151-162. [CrossRef]

12. Chen, F.; Drezner, Z.; Ryan, J.K.; Simchi-Levi, D. Quantifying the bullwhip effect in a simple supply chain: The impact of forecasting, lead times, and information. Manag. Sci. 2000, 46, 436-443. [CrossRef]

13. Chen, F.; Ryan, J.K.; Simchi-Levi, D. The impact of exponential smoothing forecasts on the bullwhip effect. Nav. Res. Logist. 2000, 47, 269-286. [CrossRef]

14. Luong, H.T. Measure of bullwhip effect in supply chains with autoregressive demand process. Eur. J. Oper. Res. 2007, 180, 1086-1097. [CrossRef]

15. Wang, J.L.; Kuo, J.H.; Chou, S.Y.; Wang, S.Z. A comparison of bullwhip effect in a single-stage supply chain for auto correlated demands when using Correct, MA, and EWMA methods. Expert Syst. Appl. 2010, 37, 4726-4736. [CrossRef]

16. Ma, Y.; Wang, N.; Che, A.; Huang, Y.; Xu, J. The bullwhip effect on product orders and inventory: A perspective of demand forecasting techniques. Int. J. Prod. Res. 2013, 51, 281-302. [CrossRef] 
17. Bray, R.L.; Mendelson, H. Information transmission and the bullwhip effect: An empirical investigation. Manag. Sci. 2012, 58, 860-875. [CrossRef]

18. Csik, A.; Foldesi, P. A bullwhip type of instability induced by time varying target inventory in production chains. Int. J. Innov. Comput. Inf. Control 2012, 8, 5885-5897.

19. Costantino, F.; Di Gravio, G.; Shaban, A.; Tronci, M. Inventory control system based on control charts to improve supply chain performances. Int. J. Simul. Model. 2014, 13, 263-275. [CrossRef]

20. Costantino, F.; Gravio, G.D.; Shaban, A.; Tronci, M. SPC forecasting system to mitigate the bullwhip effect and inventory variance in supply chains. Expert Syst. Appl. 2014, 42, 1773-1787. [CrossRef]

21. Martínez-Olvera, C. Entropy as an assessment tool of supply chain information sharing. Eur. J. Oper. Res. 2008, 185, 405-417. [CrossRef]

22. Durowoju, O.A.; Chan, H.K.; Wang, X. Entropy assessment of supply chain disruption. J. Manuf. Technol. Manag. 2012, 23, 998-1014. [CrossRef]

23. Duc, T.T.H.; Luong, H.T.; Kim, Y.D. Effect of the third-party warehouse on bullwhip effect and inventory cost in supply chains. Int. J. Prod. Econ. 2010, 124, 395-407.

24. Wu, Y.; Zhang, D.Z. Demand fluctuation and chaotic behaviour by interaction between customers and suppliers. Int. J. Prod. Econ. 2007, 107, 250-259. [CrossRef]

25. Hwarng, H.B.; Xie, N. Understanding supply chain dynamics: A chaos perspective. Eur. J. Oper. Res. 2008, 184, 1163-1178. [CrossRef]

26. Hwarng, H.B.; Yuan, X. Interpreting supply chain dynamics: A quasi-chaos perspective. Eur. J. Oper. Res. 2014, 233, 566-579. [CrossRef]

27. Fang, Y.; Shou, B. Managing supply uncertainty under supply chain Cournot competition. Eur. J. Oper. Res. 2015, 243, 156-176. [CrossRef]

28. Li, T.; Ma, J. Complexity analysis of the dual-channel supply chain model with delay decision. Nonlinear Dyn. 2014, 78, 2617-2626. [CrossRef]

29. Bashkirtseva, I.; Ryashko, L. Sensitivity analysis of stochastic attractors and noise-induced transitions for population model with Allee effect. Chaos Interdiscip. J. Nonlinear Sci. 2011, 21, 047514. [CrossRef] [PubMed]

30. Guo, K.; Jiang, J.; Xu, Y. Semi-analytical expression of stochastic closed curve attractors in nonlinear dynamical systems under weak noise. Commun. Nonlinear Sci. Numer. Simul. 2016, 38, 91-101. [CrossRef]

31. Bashkirtseva, I.; Ryashko, L. Stochastic sensitivity analysis of the attractors for the randomly forced ricker model with delay. Phys. Lett. A 2014, 378, 3600-3606. [CrossRef]

32. Galor, O. Discrete Dynamical Systems; Springer: Berlin/Heidelberg, Germany, 2007.

33. Han, Z.; Ma, J.; Si, F.; Ren, W. Entropy Complexity and Stability of a Nonlinear Dynamic Game Model with Two Delays. Entropy 2016, 18, 317. [CrossRef]

34. Ma, J.; Zhang, J. Price game and chaos control among three oligarchs with different rationalities in property insurance market. Chaos 2012, 22, 1776. [CrossRef] [PubMed]

35. Ma, J.; Xie, L. The comparison and complex analysis on dual-channel supply chain under different channel power structures and uncertain demand. Nonlinear Dyn. 2016, 83, 1379-1393. [CrossRef]

36. Guan, X.; Chen, C.; Peng, H.; Fan, Z. Time-delayed feedback control of time-delay chaotic systems. Int. J. Bifurc. Chaos 2003, 13, 193-205. [CrossRef]

(C) 2017 by the authors; licensee MDPI, Basel, Switzerland. This article is an open access article distributed under the terms and conditions of the Creative Commons Attribution (CC BY) license (http:/ / creativecommons.org/licenses/by/4.0/). 